\title{
Clustering with two-word stimuli each composed of a categorized and a noncategorized word
}

\author{
BARBARA S. MUSGRAVE AND SUSAN ALLEN ${ }^{1}$, \\ DEPARTMENT OF PSYCHOLOGY, SMITH COLLEGE, \\ Northampton, Mass. 01060
}

For a free-recall task, words of high conceptual similarity $(H)$ were each paired with a word of low conceptual similarity $(L)$. These word pairs were written either side by side as two-word stimuli, or consecutively one below the other as one-word stimuli. All responses were written as a list of single words, recalled in any order. More $H$ words were recalled than $L$ words. $H$ words clustered by category. Also, LH pairs of words presented side by side clustered increasingly over three trials; whereas, the same words presented consecutively did not.

In the free recall of lists of single-word stimuli, groups of words which are related categorically are typically reproduced in clusters (e.g., Bousfield \& Cohen, 1956; Puff, 1966). Recently, several kinds of verbal learning and behavior experiments have used lists of stimuli each of which comprised two or more discrete verbal items, thus permitting the study of organizing or coding processes of a somewhat complex sort, such as abstraction (Musgrave \& Cohen, 1966), cue selection (e.g., Cohen \& Musgrave, 1964), and word associations to multi-word stimuli (e.g., Cramer, 1964 Musgrave \& Cohen, 1967). The present experiment investigated clustering tendencies in the free recall of lists of two-word stimuli, one word of which belonged to a conceptual category represented by other words elsewhere in the list, and one word of which had little, if any, semantic relationship to the words in any other stimulus but, by its position in the learning lists, was paired with a categorized word by spatial and/or temporal contiguity.

Design and materials. Three conditions differed in terms of the lists used. Lists for the low-high condition (LH) contained 32 two-word stimuli, with the word on the left-hand side of each stimulus of low conceptual similarity (L) and the word on the right-hand side of high conceptual similarity (H). Eight words of high normative popularity in each of four categoriesvegetables, insects, musical instruments, and fish-were selected (Cohen, Bousfield, \& Whitmarsh, 1957). Thirty-two noncategorized words were selected to be paired with each of the foregoing words. matched in terms of number of letters, and meaningfulness (local, unpublished norms). As far as could be ascertained, each noncategorized word was not related conceptually nor by word-association elicitation to other words in the list. Each category appeared in blocked form within the list-i.e., all eight stimuli containing a word from a given category occurred consecutively. Three orders of the list presented the four categories in different orders, and also randomized the order of the stimuli within each categorized block of eight.

The second condition $(\mathrm{L} / \mathrm{H})$ was exactly the same as the $\mathrm{LH}$ condition with one exception: four of the eight stimulj in each block were "flipped over" HL pairs rather than LH pairs.

The third condition (SW) presented the words of the LH list as 64 single words. The tluree differemt orderings of the words in the LH lists were exactly maintained in the SW lists. except that each $\mathrm{H}$ word of an LH stimulus pair followed its $L$ word consecutively rather than the two words being presented simultaneously side by side.

Booklets presented the lists of each condition in the three different orders, each order constituting a trial. Each list appeared in a colunm centered on $8 \mathrm{x}$ 11 in. paper, with the 32-item $\mathrm{LH}$ and $\mathrm{L} / \mathrm{H}$ lists each accommodated on a single page, and the 64-item SW list requiring two consecutive pages. Large, cardboard shields each had a slot in the center narrow enough to reveal only one stimulus at a time. Response sheets were ruled $8 \times 11$ in. paper.

Subjects. Forty-five undergraduate women, all native English speakers, served as voluntecrs in groups of three or more, with a total of 15 assigned to each condition.

Procedure The Ss were asked to read the list one stimulus at a time as it was revealed in the slot in the shicld noved down the page. and then to try to reproduce the words of the list, written one word per line in a single-word column on the ruled response sheets with the words recalled in any order. The Fi paced Ss, allowing those in the $\mathrm{LH}$ and $\mathrm{L} / \mathrm{H}$ conditions 6 sec for each of the 32 two-word stimuli presented on a learning trial, and those in the SW condition $3 \mathrm{sec}$ for each of their 64 one-word stimuli. Five min were provided for each recall in all three conditions.

Results and Discussion. The responses were examined (a) for the number of $\mathrm{H}$ vs $\mathrm{L}$ words recalled, and (b) for two kinds of clustering.

Number of words recalled. Table 1 presents the means and SDs for the number of $L$ and $H$ words recalled per trial in each condition. The $\mathrm{H}$ words were better recalled than the $\mathrm{L}$ words with the degree of conceptual similarity, within-Ss main effect significant at the .001 level $(F=103.23 . \mathrm{df}=1 / 42)$. Also, recall of both kinds of words increased with trials $(F=596.98, \mathrm{df}=2 / 84$, $\mathrm{p}<.001)$. However, there was a significant interaction between these two main effects $(F=14.09$, $\mathrm{df}=2 / 84, p<.001)$, with the increase in recall steeper per trial for $L$ than for $H$ words. However, Wilcoxon tests of the appropriate pairs indicated that in each of the three conditions, $H$ words were recalled significantly $(p<.01)$ more of ten than $L$ words on each trial. These findings are in agreement with those of previous studies using single-word stimuli of $\mathrm{H}$ and $\mathrm{L}$ conceptual similarity.

Clustering. Clustering was scored for related words written one below another in recall. Thus, if three fish names appeared consecutively, the cluster score was two. There were two kinds of relatedness: by category (Cat), and by stimulus-pairing (St-pr). The St-pr words were two words which during learning trials liad been presented simultaneously side by side in a horizontal line as a spatially contiguous compound stimulus for the $\mathrm{LH}$ and $\mathrm{L} / \mathrm{H}$ conditions; or, for the SW condition, the same pairs of words presented one below the other vertically as two stimuli which were seen one at a time, but were temporally contiguous.

Because there were eight words in each of four categories, the highest possible Cat cluster score was 28; whereas the highest possible St-pr score was 32 cone point for each of 32 two-word sets). Therefore, for comparison the cluster scores were converted to per cents of possible scores.

Initial examination of the data showed that Cat clustering exceeded St-pr clustering on Trial 1 for all conditions. On Trials 2 and $3 \mathrm{St}$-pr clustering for the SW condition remained negligible. with Cat clustering increasing substantially: but for the LH and $\mathrm{L} / \mathrm{H}$ conditions, St-pr clustering increased more rapidly than and eventually exceeded Cat clustering. Closer examination of the data for the two latter conditions indicated that this comparison between kinds of cluster was. in one sense, an artifict of the scoring system. That is, as the St-pr words began to alppcalt citler above or below their appropriate eategorized words, the (at scores necessarily decreased as these words were no longer consecutive. Not revealed by this method of scoring was the fuct that despite the interlarding of St-pr words. the words of a given category tended to be recalled in blocks. Therefore, the scoring method was

Table 1

Means and SDs for Number of Words Recalled by Degree of Conceptual Similarity, by Condition, and by Trial

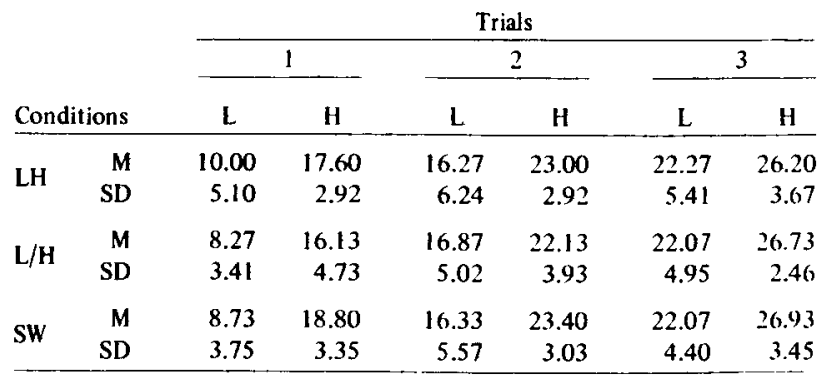


Table 2

Means and SDs for Per Cent of Clustering by Category vs by Stimulus-pairing, by Condition, and by Trial

\begin{tabular}{|c|c|c|c|c|c|c|c|}
\hline & & & & & & & \\
\hline & & & 1 & & 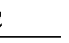 & & \\
\hline Cond & & Cat & St-pr & Cat & St-pr & Cat & St-pr \\
\hline $\mathrm{H}$ & $\mathrm{M}$ & .28 & .13 & .35 & .26 & .32 & .39 \\
\hline $\mathrm{LH}$ & SD & .13 & .12 & .18 & .22 & .20 & .23 \\
\hline$/ \mathrm{H}$ & $\mathbf{M}$ & .26 & .15 & .28 & .33 & .32 & .45 \\
\hline $\mathrm{L} / \mathrm{H}$ & SD & .21 & .14 & .22 & .25 & .20 & .26 \\
\hline & $M$ & .37 & .01 & .55 & .02 & .67 & .03 \\
\hline SW & SD & .14 & .02 & .15 & .02 & .13 & .06 \\
\hline
\end{tabular}

changed to score one cluster point for any two Cat words which either were written consecutively, or were separated by either one or two noncategorized words provided these were the appropriate St-pr words for either the preceding or following Cat word. All following results and discussion are based on this method of scoring.

Means and SDs for per cent cluster scores by kind of cluster, by condition, and by trials are presented in Table 2. An analysis of variance showed that the significant terms were the two within-Ss main effects of Trials $(F=102.40, d f=2 / 84, p<.001)$, and Kind of cluster $(\mathrm{F}=17.07, \mathrm{df}=1 / 42, \mathrm{p}<.001)$; the interaction of Kind of cluster by Kind of list $(F=14.38, \mathrm{df}=2 / 42, \mathrm{p}<.001)$; and the triple interaction of Kind of cluster by Kind of list by Trials ( $F=$ 10.70 , df $=4 / 84, p<.001$ ). For the $S W$ condition, Cat clustering exceeded St-pr clustering $(p<.01)$ on each trial. For the other two conditions, the two kinds of cluster differed significantly ( $p<$ .05 ) only on Trial 1 for the LH condition.

A general interpretation of these clustering results might be that although Ss had been instructed only to recall as many single words as possible in any order, and the learning lists had been presented in three different orders both for order of the categories and of words within categories, Ss tended to reproduce in single-word columns as much of the structure of the learning lists as had been salient in the different conditions. For the LH and $\mathrm{L} / \mathrm{H}$ groups, both the blocks of categorized words and the horizontal stimulus pairing of $\mathrm{L}$ with $\mathrm{H}$ words was substantially reproduced by the third trial. However, for the LH condition, the decrease in Cat clustering from the second to the third trials may indicate some disruption of category recall by the attempt to reproduce St-pr clusters. For the $\mathrm{SW}$ condition, Cat clustering increased steeply, with St-pr clustering occurring only rarely throughout three trials. Although the $\mathrm{H}$ word of the pair always followed its $L$ word for this condition, the order of pairs within a categorized block changed, and it is possible that the pairs of words presented one below the other were not perceived as pairs.

The findings of this experiment indicate that presentational format is an influential factor in organizational tendencies in free recall.

\section{REFERENCES}

BOUSFIELD, W. A., \& COHEN, B. H. Clustering in recall as a function of the number of word categories in stimulus-word lists. J. gen. PsychoL, 1956, 54, 95-106.

COHEN, B. H., BOUSFIELD, W. A., \& WHITMARSH, G. A. Cultural norms for verbal items in 43 categories. Under Contract Nonr-631(00), between the Office of Naval Research and the Univ. of Connecticut, 1957. (Tech. Rep. No. 22.)

COHEN, JEAN C., \& MUSGRAVE, BARBARA S. Effect of meaningfulness on cue selection in verbal paired-associate learning. J. exp. Psychol, 1964, $68,284-291$.

CRAMER, PHEBE. Successful mediated priming via associative bonds. Psychol Rep., 1964, 15, 235-238.

MUSGRAVE, BARBARA S., \& COHEN, JEAN C. Abstraction in verbal paired-associate learning. J. exp. Psychol, 1966, 71, 1-8.

MUSGRAVE, BARBARA S., \& COHEN, JEAN C. Word associations to compound stimuli under two presentational methods. Psychon. Sci, 1967, 9(6), 315-316.

PUFF, C. R. Clustering as a function of the sequential organization of stimulus word lists. J. verbal Learn, verbal Behav., 1966, 5, 503-506.

\section{NOTE}

1. This research was supported in part by PHS Research Grant, MH-08156 from the National Institute of Mental Health, and in part by a grant to the Trustees of the Smith College from the Albert P. Sloan Foundation. 